\title{
TITLE:
}

\section{$<$ ERRATUM $>$ A Female Bonobo Sleeping on the Ground after Daytime Birth and its Implications}

$\operatorname{AUTHOR}(S)$ :

Ryu, Heungjin

\section{CITATION:}

Ryu, Heungjin. <ERRATUM>A Female Bonobo Sleeping on the Ground after Daytime Birth and its Implications. Pan Africa News 2018, 25(1): 1313

ISSUE DATE:

2018-06

URL:

http://hdl.handle.net/2433/233031

RIGHT:

Copyright (C) Pan Africa News. 


\title{
A Female Bonobo Sleeping on the Ground after Daytime Birth and its Implications
}

\author{
Heungjin Ryu \\ Pan Africa News 24(2), 9-13 (2017)
}

Owing to a technical error, corresponding e-mail address was typed incorrectly as ryu.heungjin.26v@st.kyoto-u.ac.jp instead of ryu.heungjin.26v@kyoto-u.jp in the print and the KURENAI versions. This error has been corrected in the HTML version at http://mahale.main.jp/PAN/24_2/24(2)_01.html. 